DOI: https://doi.org/10.24127/ajpm.v8i1.1684

\title{
PENERAPAN PENDEKATAN PENEMUAN TERBIMBING UNTUK MENINGKATKAN KEMAMPUAN PEMAHAMAN KONSEP MATEMATIS SISWA
}

\author{
Syahlan Romadon ${ }^{1}$, Ali Mahmudi ${ }^{2}$ \\ ${ }^{1,2}$ Pendidikan Matematika, Universitas Negeri Yogyakarta \\ E-mail: $\quad$ syahlan.romadon2016@student.uny.ac.id ${ }^{l)}$ \\ alimahmudi@uny.ac.id ${ }^{2}$
}

Received 5 December 2018; Received in revised form 24 March 2019; Accepted 3 May 2019

\begin{abstract}
The purpose of this study is to reveal the effectiveness of learning with guided inquiry approach in term of mathematical concepts understanding, and to find out with approach is more effective between learning with guided inquiry approach and ordinary learning in term of mathematical concepts understanding. This research was quasi-experimental research study whose population covered all grade VIII students of SMP Unggulan Aisyiyah Bantul. Class VIII Hafshah and VIII Hawa were established as the sample. Class VIII Hawa as an experimental class was taught with guided inquiry approach. Class VIII Hafshah as a control class was taught with ordinary learning. The results of the study at a significance level of $5 \%$, shows that the learning with guided inquiry approach and ordinary learning was effective in term of mathematical concept understanding. Learning with guided inquiry approach was more effective than ordinary learning in term of mathematical concept understanding.
\end{abstract}

Keywords: guided inquiry; mathematical concept understanding.

\section{PENDAHULUAN}

Pendidikan merupakan suatu hal yang penting bagi kehidupan bangsa. Menurut Undang-Undang RI Nomor 20 Tahun 2003 tentang Sistem Pendidikan Nasional Pasal 3, pendidikan nasional berfungsi mengembangkan kemampuan dan membentuk watak serta peradaban bangsa yang bermartabat dalam rangka mencerdaskan kehidupan bangsa, bertujuan untuk berkembangnya potensi peserta didik agar menjadi manusia yang beriman dan bertakwa kepada Tuhan Yang Maha Esa, berakhlak mulia, sehat, berilmu, cakap, kreatif, mandiri, dan menjadi warga negara yang demokratis serta bertanggung jawab. Untuk mewujudkan tujuan pendidikan nasional tersebut diperlukan profil kualifikasi kemampuan lulusan yang dituangkan dalam standar kompetensi lulusan.
Berdasarkan Permendikbud RI Nomor 20 Tahun 2016 tentang Standar Kompetensi Lulusan setiap lulusan satuan pendidikan dasar dan menengah memiliki kompetensi pada tiga dimensi yaitu sikap, pengetahuan, dan keterampilan. Pada dimensi pengetahuan, dibutuhkan pengetahuan faktual, konseptual, prosedural, dan metakognitif.

Salah satu yang harus dicapai siswa pada dimensi pengetahuan ini adalah pengetahuan konseptual. Siswa harus paham denga konsep - konsep yang ada dalam matematika. Pemahaman konsep tersebut perlu ditanamkan kepada peserta didik sejak dini yaitu sejak anak tersebut masih duduk di bangku Sekolah Dasar (SD) maupun bagi siswa Sekolah Menengah Pertama (SMP). Pada tingkat tersebut siswa dituntut mengerti tentang definisi, pengertian, cara pemecahan masalah 
maupun pengoperasian matematika secara benar, karena akan menjadi bekal dalam memperlajari matematika pada jenjang pendidikan yang lebih tinggi.

Kemampuan pemahaman konsep matematis adalah kemampuan pokok dan mendasar yang harus dimiliki siswa agar mampu memiliki kemampuan matematis yang lebih tinggi serta mampu mengklasifikasikan sesuatu berdasarkan definisinya. Seperti yang disampaikan Lestari \& Surya (2017) bahwa kemampuan pemahaman konsep adalah kemampuan utama yang harus dimiliki oleh siswa untuk memiliki kemampuan lain seperti kemampuan pemecahan masalah, kemampuan komunikasi, dan kemampuan representasi matematika. Jadi, kemampuan pemahaman konsep matematis ini sangat penting dan sangat berpengaruh pada perkembangan kemampuan matematis yang lebih tinggi.

Konsep merupakan batasan yang jelas yang membedakan antara contoh dan bukan contoh. Konsep yang jelas memungkinkan adanya klasifikasi berdasarkan definisi tertentu. Menurut Yuliani \& Saragih (2015) konsep adalah ide abstrak yang memungkinkan untuk mengklasifikasikan objek menjadi contoh dan non-contoh, yang biasanya dinyatakan oleh definisi. Paham tentang konsep matematika tidak hanya sekedar hafal atau mampu mengikuti prosedur dari contoh penyelesaian yang sudah ada. Paham konsep matematika berarti dapat menjelaskan, menemukan bukti, memberi contoh dan bukan contoh, menggeneralisasi, mengaplikasikan, menganalogikan, dan merepresentasikan konsep matematika (Alifiani, 2017).

Menurut Lauritzen (2012) bahwa pemahaman konseptual yang mendalam tidak hanya berdasarkan prosedur yang rinci, tetapi juga berkaitan dengan relasi. Siswa memahami konsep matematika saat siswa mampu mengetahui apa yang disampaikan dengan bahasa matematika. Kemampuan pemahaman konsep matematis mampu berkembang dengan adanya definisi dan batasan jelas yang dipahami oleh guru dan siswa. Ashley, Schaap, \& de Bruijn (2016) menyatakan bahwa untuk meningkatkan pemahaman konsep dari suatu disiplin ilmu diperlukan definisi yang membuat guru dan siswa menyadari tentang apa yang diperlukan untuk mengembangkan pemahaman yang mendalam.

Kenyataan di lapangan, pemahaman konsep matematis siswa masih relatif rendah. Salah satu bukti bahwa kemampuan pemahaman konsep matematis siswa masih rendah adalah dari hasil daya serap ujian nasional. Berdasarkan Tabel 1 terlihat bahwa daya serap ujian nasional khususnya materi geometri dan pengukuran masih relatif rendah. Artinya, relatif banyak siswa yang belum paham konsep matematika.

Tabel 1. Daya Serap Ujian Nasional Kabupaten Bantul

\begin{tabular}{cc}
\hline $\begin{array}{c}\text { Tahun } \\
\text { Pelajaran }\end{array}$ & $\begin{array}{c}\text { Daya Serap Geometri } \\
\text { dan Pengukuran }\end{array}$ \\
\hline $2014 / 2015$ & 56,23 \\
$2015 / 2016$ & 52,81 \\
$2016 / 2017$ & 59,57 \\
\hline
\end{tabular}

Rendahnya pemahaman konsep tidak hanya ditunjukkan dari hasil ujian nasional di Indonesia saja. Saleh (2011) menyatakan bahwa siswa benar - benar memiliki masalah dengan pemahaman konsep dan meskipun nilai siswa tinggi tidak bisa digunakan untuk jaminan bahwa siswa memahami konsep secara matang. Hal ini menunjukkan bahwa kurangnya pemahaman konsep pada siswa berdampak pada nilai siswa. Meskipun demikian, nilai yang tinggi 
juga tidak menjamin pemahaman konsep yang matang bagi siswa. Horzum \& Ertekin (2017) menegaskan bahwa pentingnya pengajaran dan pembelajaran konsep matematika tidak dapat diabaikan.

Terdapat beberapa penelitian lain yang mendukung bahwa pemahaman konsep yang dimiliki siswa masih kurang. Murizal (2012) dalam penelitiannya menyatakan bahwa masih banyak peserta didik yang kesulitan dalam memahami konsep matematika. Penelitian Ningsih (2017) menyampaikan bahwa siswa masih sulit dalam memahami konsep matematika.

Setelah menganalisis berbagai permasalahan tersebut, diperlukan usaha untuk memperbaiki kualitas pembelajaran di sekolah. Pada Permendikbud Nomor 22 tahun 2016 tentang Standar Proses Pendidikan Dasar dan Menengah sudah ditawarkan beberapa pendekatan pembelajaran. Pendekatan pembelajaran yang ditawarkan tentunya sudah sesuai dengan standar kompetensi lulusan yang akan dicapai. Pada Permendikbud Nomor 22 tahun 2016 disebutkan bahwa kegiatan inti menggunakan model pembelajaran, metode pembelajaran, media pembelajaran, dan sumber belajar yang disesuaikan dengan karakteristik peserta didik dan mata pelajaran. Pemilihan pendekatan tematik dan/atau tematik terpadu dan/atau saintifik dan/atau inkuiri dan penyingkapan (discovery) dan/atau pembelajaran yang menghasilkan karya berbasis pemecahan masalah (project based learning) disesuaikan dengan karakteristik kompetensi dan jenjang pendidikan.

Pada tingkat sekolah menengah akan lebih cocok jika penemuan dikonsep dengan bentuk penemuan terbimbing (guided inquiry). Bimbingan yang dimaksud bisa berasal dari segala sumber, baik bimbingan dari guru, teman sebaya, atau dari media pembelajaran yang digunakan sehingga memunculkan proses diskusi. Diskusi berguna untuk memperoleh pemahaman konsep yang lebih besar atau membuka wawasan dari berbagai sudut pandang (Schunk, 2012).

Tujuan penelitian ini adalah untuk mengetahui manakah yang lebih efektif peningkatan kemampuan pemahaman konsep matematis siswa pada pembelajaran dengan pendekatan penemuan terbimbing atau pembelajaran biasa. Hipotesis yang diajukan adalah bahwa pendekatan penemuan terbimbing lebih efektif dibandingkan dengan pembelajaran biasa dalam meningkatkan pemahaman konsep matematika.

\section{METODE PENELITIAN}

Penelitian ini merupakan penelitian kuantitatif dengan metode penelitian eksperimen semu. Model rancangan eksperimen yang digunakan adalah pretest-postest control group design yang akan digunakan untuk mengetahui keefektifan pembelajaran dengan pendekatan penemuan terbimbing untuk meningkatkan kemampuan pemahaman konsep matematis siswa. Desain yang digunakan seperti pada Tabel 2.

Tabel 2. Desain Penelitian

\begin{tabular}{lllll}
\hline Eksperimen & $\mathrm{R}$ & $\mathrm{O}_{1}$ & $\mathrm{X}$ & $\mathrm{O}_{2}$ \\
\hline Kontrol & $\mathrm{R}$ & $\mathrm{O}_{3}$ & $\mathrm{~K}$ & $\mathrm{O}_{4}$ \\
\hline
\end{tabular}

Keterangan:

R: Kelas dipilih secara acak

$\mathrm{O}_{1}, \mathrm{O}_{3}$ : Pemberian pretest

$\mathrm{X}$ : Perlakuan (Penerapan pendekatan penemuan terbimbing)

$\mathrm{K}$ : Penerapan pembelajaran biasanya

$\mathrm{O}_{2}, \mathrm{O}_{4}$ : Pemberian posttest 
Variabel pada penelitian ini adalah variabel bebas dan variabel terikat. Variabel bebas pada penelitian ini adalah pembelajaran dengan pendekatan penemuan terbimbing. Variabel terikat pada penelitian ini adalah kemampuan pemahaman konsep matematis.

Penelitian ini dilaksanakan di SMP Unggulan Aisyiyah Bantul. Populasi dalam penelitian ini adalah seluruh siswa kelas VIII SMP Unggulan Aisyiyah Bantul. Sampel yang digunakan adalah 2 kelas yang diambil secara acak yaitu kelas VIII Hawa sebanyak 28 siswa dan kelas VIII Hafshah sebanyak 27 siswa.

Instrumen yang digunakan utuk mengumpulkan data pada penelitian ini adalah soal tes pemahaman konsep matematis. Soal berupa soal pilihan ganda dan uraian yang diberikan di awal dan di akhir pembelajaran.

Teknik analisis data menggunakan uji $t$ dua sampel independen yang bertujuan untuk mengetahui ada tidaknya perbedaan keefektifan pembelajaran baik sebelum maupun sesudah perlakuan yang diawali dulu dengan uji asumsi normalitas dan homogenitas. Setelah dilakukan perlakuan, digunakan uji t satu sampel untuk mengetahui mana yang lebih efektif antara pembelajaran dengan pendekatan penemuan terbimbing dengan pembelajaran biasanya. Pada penelitian ini, pembelajaran dengan pendekatan penemuan terbimbing dikatakan efektif ditinjau dari kemampuan pemahaman konsep matematis jika nilai statistik uji $\mathrm{t}$ menghasilkan nilai signifikansi lebih dari 0,05 dengan standar nilai dalam uji beda dua rataan adalah nilai kriteria ketuntasan minimal (KKM) sekolah, yaitu 75 .

\section{HASIL PENELITIAN DAN PEMBAHASAN}

Pada penelitian ini diperoleh hasil berupa nilai pretes dan posttest kemampuan pemahamn konsep matematis. Adapun hasil disajikan pada Tabel 3.

Tabel 3. Data Hasil Pretest dan Posttest

\begin{tabular}{ccccc}
\hline \multirow{2}{*}{ Deskripsi } & \multicolumn{2}{c}{ Eksperimen } & \multicolumn{2}{c}{ Kontrol } \\
\cline { 2 - 5 } & Pre & Post & Pre & Post \\
\hline Rerata & 40,54 & 78,57 & 40,93 & 76,73 \\
$\begin{array}{c}\text { Standar } \\
\text { deviasi } \\
\text { Nilai }\end{array}$ & 23,97 & 14,46 & 18,18 & 12,96 \\
$\begin{array}{c}\text { terendah } \\
\text { Nilai }\end{array}$ & 10 & 45 & 15 & 55 \\
tertinggi & 90 & 100 & 80 & 95 \\
\hline
\end{tabular}

Berdasarkan Tabel 3, terlihat bahwa kondisi akhir setelah pemberian perlakuan, terjadi peningkatan nilai pemahaman konsep matematis baik di kelas eksperimen maupun kelas kontrol. Pada kelas eksperimen rata - rata skor meningkat sebesar 38,03. Sedangkan pada kelas kontrol meningkat sebesar 35,80. Terlihat bahawa peningkatan di kelas eksperimen lebih besar dibandingkan dengan kelas kontrol

Data dikelompokkan berdasarkan persentase siswa yang tuntas dan tidak tuntas pada pemahaman konsep matematis siswa. Hasil pengelompokan bisa dilihat pada Tabel 4 .

Tabel 4. Banyaknya Ketuntasan Siswa

\begin{tabular}{lcccc}
\hline \multirow{2}{*}{ Deskripsi } & \multicolumn{2}{c}{ Eksperimen } & \multicolumn{2}{c}{ Kontrol } \\
\cline { 2 - 5 } & Pre & Post & Pre & Post \\
\hline Siswa & 3 & 17 & 3 & 14 \\
$\begin{array}{l}\text { Tuntas } \\
\text { Siswa }\end{array}$ & & & & \\
Tidak & 25 & 9 & 24 & 13 \\
Tuntas & & & & \\
\hline
\end{tabular}

Dari Tabel 4 dapat dilihat bahwa kedua kelas tersebut hanya terdapat tiga siswa yang tuntas pada pretest 
kemampuan pemahaman konsep matematis. Namun setelah perlakuan, terdapat kenaikan yang signifikan pada posttest kemampuan pemahaman konsep matematis. Baik pada kelas eksperimen maupun kelas kontrol, siswa yang tuntas lebih banyak daripada siswa yang tidak tuntas.

Berdasarkan hasil penelitian tersebut dilakukan uji hipotesis sesuai dengan rancangan sebelumnya. Langkah awal dalam menganalisis data pada penelitian ini adalah melihat apakah kondisi awal dari kelas eksperimen dan kelas kontrol bisa dikatakan sama atau berbeda, sehingga perlu dilakukan uji beda rataan dari dua kelas tersebut. Sebelum melakukan pengujian, terdapat asumsi yang harus dipenuhi, yaitu uji asumsi normalitas dan uji asumsi homogenitas.

Uji asumsi normalitas yang dilakukan dengan uji Kolmogorov Smirnov menghasilkan nilai 0,134 dengan signifikansi 0,200 pada kelas eksperimen dan nilai 0,115 dengan signifikansi 0,200 pada kelas kontrol. Signifikansi yang dihasilkan lebih dari 0,05, baik pada kelas eksperimen maupun kelas kontrol, sehingga dapat disimpulkan bahwa data dari kedua kelas tersebut berdistribusi normal.

Uji asumsi homogenitas yang dilakukan dengan uji Leneve menghasilkan nilai 2,486 dengan signifikansi 0,121 . Signifikansi yang dihasilkan lebih dari 0,05 , sehingga dapat disimpulkan bahwa data tersebut homogen. Karena data homogen, selanjutnya diuji dengan uji kesamaan dua rata-rata.

Uji kesamaan dua rata - rata yang dilakukan dengan uji dua sampel independen menghasilkan nilai $-0,068$ dengan signifikansi 0,946 . Signifikansi yang dihasilkan lebih dari 0,05, sehingga dapat disimpulkan bahwa terdapat kesamaan nilai pada kedua kelas.

Berdasarkan uji asumsi dan uji beda dua rata - rata, kedua kelas mempunyai nilai awal yang sama. Penelitian dilanutkan dengan pemberian perlakuan dikedua kelas. Kelas eksperimen dengan pendekatan penemuan terbimbing dan kelas kontrol dilakukan pembelajaran seperti biasanya. Setelah perlakuan selesai dilakukan posttest yang kemudian di uji hipotesis seperti data pretest.

Uji asumsi normalitas yang dilakukan dengan uji Kolmogorov Smirnov menghasilkan nilai 0,147 dengan signifikansi 0,128 pada kelas eksperimen dan nilai 0,163 dengan signifikansi 0,064 pada kelas kontrol. Signifikansi yang dihasilkan lebih dari 0,05 , baik pada kelas eksperimen maupun kelas kontrol, sehingga dapat disimpulkan bahwa data dari kedua kelas tersebut berdistribusi normal.

Uji asumsi homogenitas yang dilakukan dengan uji Leneve menghasilkan nilai 0,357 dengan signifikansi 0,553. Signifikansi yang dihasilkan lebih dari 0,05 , sehingga dapat disimpulkan bahwa data tersebut homogen. Karena data homogen, selanjutnya diuji dengan uji kesamaan dua rata-rata.

Uji kesamaan dua rata - rata yang dilakukan dengan uji dua sampel independen menghasilkan nilai 0,664 dengan signifikansi 0,510. Signifikansi yang dihasilkan lebih dari 0,05, sehingga dapat disimpulkan bahwa terdapat kesamaan nilai pada kedua kelas.

Berdasarkan uji hipotesis yang dilakukan didapatkan hasil bahwa terdapat kesamaan pada kedua kelas baik kelas eksperimen maupun kelas kontrol. Dengan kesamaan nilai, perlu diuji lanjut untuk mengetahui mana yang lebih efektif diantara kedua kelas 
tersebut. Uji yang dilakukan adalah uji t satu sampel.

Hasil uji t satu sampel pada kelas eksperimen adalah 1,307 dengan signifikansi 0,202. Hasil uji t pada kelas kontrol adalah 0,446 dengan signifikansi 0,660 . Kedua nilai signifikansi lebih dari 0,05 artinya, kedua kelas dianggap senilai dengan 75 . Nilai t pada kelas eksperimen lebih besar daripada nilai t pada kelas kontrol.

Berdasarkan hasil tersebut dapat disimpulkan bahwa kedua pembelajaran efektif untuk meningkatkan kemampuan pemahaman konsep matematis siswa, tetapi kelas eksperimen yaitu pembelajaran dengan pendekatan penemuan terbimbing lebih efektif dibandingkan dengan pembelajaran biasa. Hal ini terlihat dari lebih besarnya nilai t pada kelas eksperimen dibandingkan nilai t pada kelas kontrol.

Hasil penelitian ini sesuai dengan hipotesis awal bahwa pembelajaran dengan pendekatan penemuan terbimbing lebih efektif untuk meningkatkan kemampuan pemahaman konsep matematis siswa. Pada pembelajaran dengan penemuan terbimbing terdapat langkah - langkah yang mengarahkan siswa untuk menemukan konsep. Pada langkah merumuskan hipotesis, siswa akan berkolaborasi bersama teman sekelompoknya untuk menduga jawaban atau konsep yang akan didapat dari permasalahan yang disajikan. Pada langkah mengumpulkan data dan menguji hipotesis akan mengarahkan siswa agar mencari informasi sebanyak - banyaknya serta menguji dugaan suatu konsep matematis. Siswa akan mengaitkan informasi yang didapatkan sehingga siswa mengaitkan konsep konsep yang berkaitan dengan informasi yang didapatkan. Dengan demikian akan mampu menguatkan siswa dalam memahami konsep - konsep matematis.
Hasil ini sejalan dengan penelitian Karim (2011) yang menunjukkan bahwa pembelajaran penemuan terbimbing lebih baik daripada pembelajaran konvensional dalam meningkatkan kemampua pemahaman konsep siswa. Hasil ini juga sesuai dengan teori yang telah disampaikan sebelumnya. Pembelajaran penemuan terbimbing dirancang dengan melibatkan proses berpikir siswa yang dimulai dari pengalaman sehingga siswa akan diberi kesempatan sebanyak - banyaknya untuk menemukan sendiri konsep yang harus dimiliki (Khomsiatun \& Retnawati, 2015)

\section{KESIMPULAN DAN SARAN}

Berdasarkan dari hasil analisis data dan pembahasan maka dapat disimpulkan bahwa pembelajaran dengan pendekatan penemuan terbimbing dan pembelajaran biasa efektif ditinjau dari kemampuan pemahaman konsep matematis. Pembelajaran dengan pendekatan penemuan terbimbing terbukti lebih efektif dibandingkan dengan pembelajaran biasa.

Saran yang dapat diberikan dari hasil penelitian ini adalah diharapkan kepada guru matematika untuk menerapkan pembelajaran dengan pendekatan penemuan terbimbing sebagai alternatif pembelajaran untuk mencapai tujuan belajar. Selain itu, penggunaan media pembelajaran dan variasi pembelajaran dengan diskusi kelompok bisa meningkatkan kemampuan pemahaman kosep matematis siswa.

\section{DAFTAR PUSTAKA}

Alifiani, A. (2017). Penerapan Model Pembelajaran NHT-TGT Untuk Meningkatkan Motivasi Dan Pemahaman Konsep Materi 
DOI: https://doi.org/10.24127/ajpm.v8i1.1684

Matematika SMA. Jurnal Riset Pendidikan, 11-20.

Ashley, S., Schaap, H., \& de Bruijn, E. (2016). Defining Conceptual Understanding for Teaching in International Business. Journal of Teaching in International Business, 106-123.

Horzum, T., \& Ertekin, E. (2017). Prospective mathematics teachers' understanding of the base concept*. International Journal of Mathematical Education in Science and Technology, 1-21.

Karim, A. (2011). Penerapan Metode Penemuan Terbimbing dalam Pembelajaran Matematika untuk Meningkatkan Pemahaman Konsep dan Kemampuan Berpikir Kritis Siswa Sekolah Dasar. Proceedings Simantap.

Lauritzen, P. (2012). Conceptual and Procedural Knowledge of Mathematical Functions. Joensuu: University of Eastern Finland.

Lestari, L., \& Surya, E. (2017). The Effectiveness of Realistic Mathematics Education Approach on Ability of Students , Mathematical Concept Understanding. International Journal of Sciences: Basic and Applied Research, 91-100.

Murizal, A., Yarman, \& Yerizon. (2012). Pemahaman Konsep Matematis dan Model Pembelajaran Quantum. Jurnal Pendidikan Matematika, 19-23.

Ningsih, S.Y. (2017). Peningkatan Kemampuan Pemahaman Konsep Siswa Melalui
Pendekatan Matematika Realistik Di SMP Swasta Tarbiyah Islamiyah. Journal of Mathematics Education and Science 3(1), 82-90.

Peraturan Menteri Pendidikan dan Kebudayaan Republik Indonesia No 20 Tahun 2016 Tentang Standar Kompetensi Lulusan, 20 (Mendikbud 2016).

Peraturan Menteri Pendidikan dan Kebudayaan Republik Indonesia No 22 Tahun 2016 tentang Standar Proses Pendidikan Dasar dan Menengah, 22 (Mendikbud 2016).

Saleh, S. (2011). The Level of B . Sc . Ed Students , Conceptual Understanding of Newtonian Physics. International Journal of Academic Research in Business and Social Sciences, 249-256.

Schunk, D. H. (2012). Learning theories: an educational perspective. Boston, MA: Pearson.

Undang-Undang Republik Indonesia Nomor 20 Tahun 2003 tentang Sistem Pendidikan Nasional, 20 (Republik Indonesia 2003).

Yuliani, K., \& Saragih, S. (2015). The Development of Learning Devices Based Guided Discovery Model to Improve Understanding Concept and Critical Thinking Mathematically Ability of Students at Islamic Junior High School of Medan. Journal of Education and Practice, 116128. 